\title{
A Geographic Area with Better Outcome of Esophageal Carcinoma: Is There an Effect of Ethnicity and Etiologic Factors?
}

\author{
Roham Salek $^{\mathrm{a}}$ Safa Esmailpoor Bezenjani ${ }^{d}$ Hamid Saeidi Saedi $^{\mathrm{a}}$ \\ Mohamad Hasan Hosainzad Ashkiki ${ }^{e}$ Seid Mohsen Hosainzade ${ }^{a}$ \\ Samira Mohtashami ${ }^{a}$ Monavar Afzal Aghai ${ }^{b}$ Mostafa Mehrabi Bahar ${ }^{c}$ \\ Mohamad Reza Ghavamnasiri ${ }^{a}$ \\ Departments of a Radiation Oncology, ${ }^{\mathrm{b}}$ Medical Statistics and ${ }^{\mathrm{c} S u r g e r y}$, Mashhad University of Medical Sciences, \\ Mashhad, 'd Department of Radiation Oncology, Kerman University of Medical Sciences, Kerman, \\ e Department of Radiation Oncology, Ardabil University of Medical Sciences, Ardabil, Iran
}

\section{Key Words}

Esophagus cancer $\cdot$ Outcome $\cdot$ Prognostic factors $\cdot$ Iran

\begin{abstract}
Objectives: Although Iran, and especially the northeast of the country, is known as one of the areas in the world where esophageal cancer is most prevalent, there is no information on the survival rate of patients affected with this disease in this region. To address this issue, we conducted a study comprehensive enough to provide as accurate an estimate as possible. Any finding related to survival of patients in this area may be considered representative of Iran. Methods: Esophageal cancer patients who were consecutively referred to the oncology centers of Omid and Imam Reza Hospitals from July 1997 to March 2004 were recruited for the study. Data collection included the demographical and clinical characteristics of patients in addition to treatment details. The median survival and overall survival rates, as well as the median event-free survival and event-free survival rates, were evaluated. Univariate and multivariate analyses were performed to detect any significant prognostic factors. $R \boldsymbol{e}$ sults: 1,568 patients were eligible. The Kaplan-Meier analysis
\end{abstract}

\section{KARGER}

Fax +4161306 1234 E-Mail karger@karger.ch www.karger.com
(ㄷ) 2009 S. Karger AG, Basel

$0030-2414 / 09 / 0774-0172 \$ 26.00 / 0$

Accessible online at:

www.karger.com/ocl indicates that median survival is 38 months $(95 \% \mathrm{Cl}, 26.6-$ 49.3), 5-year survival is $42 \%(38.76-46.16 \%)$, median eventfree survival is 21 months $(95 \% \mathrm{Cl}, 18.2-23.8)$ and 5-year event-free survival is $29.9 \%$ (27.07-32.67\%). The univariate analysis indicates that age, gender, tumor histology, tumor location, body mass index and disease stage are significant predictors of overall survival. However, in the multivariate analysis, disease stage is the best prognostic factor. Conclusion: The prognosis of esophagus cancer in Iran is not as dismal as in other world regions. Our treatment outcome and survival rates are much higher than those reported especially in western countries.

Copyright $\odot 2009$ S. Karger AG, Basel

Of the approximately 10 million new cases of cancer diagnosed throughout the world each year, almost 391,000 were esophagus cancers, predominantly squamous cell carcinoma (SCC), which was responsible for 355,000 deaths in 2000. In addition, esophagus cancer ranks among the 10 most common malignancies in the world $[1,2]$. Esophagus cancer rates vary substantially (about sixty-fold) from country to country, more so than any

Roham Salek, MD

Department of Radiation Oncology, Imam Reza Hospital

Mashhad University of Medical Sciences

Mashhad (Iran)

Tel. +989 153167 656, Fax +985118 545 035, E-Mail salekr@mums.ac.ir 
other malignancy. The areas of high prevalence include Asia, southern and eastern Africa and northern France, where the annual mortality rates of esophagus cancer reach up to 100 per 100,000 inhabitants [1]. One of these high-incidence areas has been identified within the Caspian littoral region of northern Iran, where the incidence rate exceeds 100 per 100,000 inhabitants [3-5].

In the 1990s, the 5-year survival rate for esophageal cancer was about $11 \%$, with little difference among histological types. Since most patients are at an advanced stage at diagnosis, the incidence and mortality rates are nearly equal. Even at an early stage of the disease, survival is relatively poor [6].

Although Iran is one of the nations in which esophagus cancer is the most prevalent, there has not been any notable published information regarding the survival of its esophagus cancer patients. Therefore, we decided to perform this study in an attempt to determine if survival in Iran differs from rates reported around the globe, and especially in western countries.

\section{Patients and Methods}

\section{Patients' Characteristics}

More than 1,600 consecutive esophageal cancer patients were referred to the Mashhad University of Medical Sciences cancer treatment centers of Omid Hospital and Imam Reza Hospital from July 1997 until March 2004. Patient medical records were analyzed and information was entered into a database. Every patient with a documented pathologic report was included. Excluded were all cases of lower esophageal adenocarcinoma with suspicious involvement of the cardia and all cases of cervical esophageal SCC with involvement of the hypopharynx. No other exclusion criteria based on clinical characteristics and treatment method were accepted.

\section{Evaluation and Statistical Analysis}

Pretreatment assessments included esophagoscopy and biopsy of the primary lesion, an esophagogram, radiological evaluation of the lung (chest X-ray or CT scan) and upper abdomen (generally sonography), complete blood count and renal and liver function tests. Patients were staged when possible based on the TNM classification of the American Joint committee for Cancer Staging (AJCC) [7]. For every patient, the treatment course was surveyed. After the completion of treatment protocols, patients were followed up at 1- to 3-month intervals during the following 1-3 years and then at longer intervals. Follow-up evaluations mainly included patient history, physical examinations and if indicated, depending on symptoms and signs, esophagogram, abdominal sonography, endoscopy and any other imaging evaluations and laboratory tests required to assess any suspicious recurrence. We tried to contact by phone or mail those who did not appear for their periodic visits. The follow-up ended in June 2006.
Table 1. Treatment modalities in the study population

\begin{tabular}{lc}
\hline Treatment modalities & Patients, $\mathrm{n}$ \\
\hline Chemoradiotherapy & $519(37 \%)$ \\
Surgery with adjuvant treatments & $555(39 \%)$ \\
Surgery alone & $79(5.6 \%)$ \\
Radiotherapy alone & $184(13 \%)$ \\
Chemotherapy alone or no treatment & $63(4.5 \%)$ \\
\hline
\end{tabular}

Overall survival was defined as the interval between the diagnostic endoscopic biopsy and the last follow-up or death from any cause. To discover any effect on overall survival, different variables of age, gender, tumor histology, tumor location, tumor grade, tumor size, extent of luminal involvement, body mass index, lag time between diagnosis and beginning of treatment and disease stage were analyzed. Event-free survival was defined as the interval between diagnostic endoscopic biopsy and the earliest event, including local recurrence, distant metastasis, second primary tumor and death from any cause. Local control in the nonsurgically treated group was assessed by endoscopic studies. Persistence or recurrence of dysphagia was not defined as local failure without pathologic proof of malignancy. For distant metastasis, the overall clinical judgment was considered sufficient and a pathologic assessment was not mandatory.

All data were analyzed by SPSS software, version 11.5. Survival analysis was measured by the Kaplan-Meier methods [8]. The log rank test was used to compare survival curves. Cox regression analysis was used to compare prognostic factors [9]. $\mathrm{p}$ values of less than 0.05 were considered as a statistically significant difference between compared groups.

\section{Results}

1,640 patients were enrolled in the study. Of these, 1,568 were eligible. Seventy patients were omitted because of invalid records (49 cases) and the aforesaid exclusion criteria (16 cases of lower-esophagus adenocarcinoma and 5 cases of upper-esophagus SCC). The median age was 61.5 years (range 17-91). The male-to-female ratio was $1.2 / 2$. Surgical staging was possible for some patients who underwent surgery. While only $1.1 \%$ of the patients were in stage I, $57 \%$ were in stage II, $41 \%$ in stage III and $4 \%$ in stage IV of the disease. As for the group which did not undergo surgery, only two stages of metastatic (IVA and IVB) and nonmetastatic disease were applicable. A variety of different treatment modalities and patient distribution are shown in table 1 . Surgery included both transthoracic (65\%) and transhiatal (35\%) esophagectomy techniques. Median doses of radiotherapy were $54 \mathrm{~Gy}(2-64 \mathrm{~Gy})$ as radical radiotherapy or chemoradiotherapy, $30 \mathrm{~Gy}$ as preoperative radiotherapy, and $50 \mathrm{~Gy}$ as postoperative radio- 


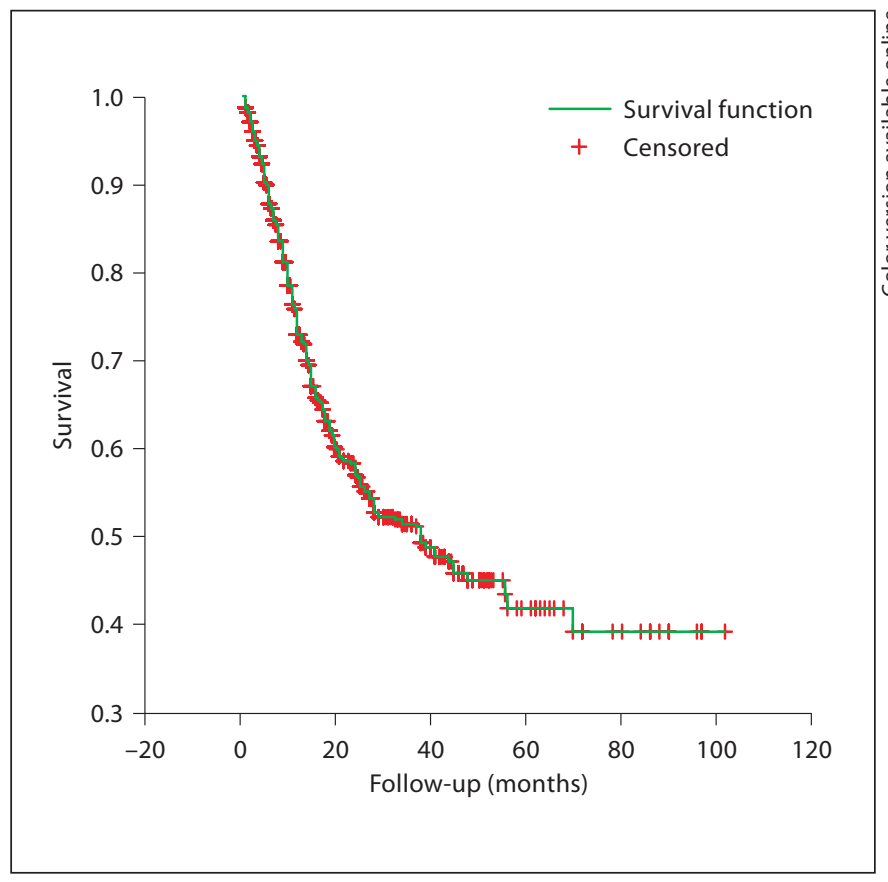

Fig. 1. Kaplan-Meier curve of overall survival.

therapy. A combination of cisplatin and 5-fluorouracil (5FU) with two schedules was the most common chemotherapy regimen (in more than $90 \%$ of the cases). First as an outpatient treatment, a bolus intravenous administration of cisplatin $25 \mathrm{mg} / \mathrm{m}^{2}$ per day and $5-\mathrm{FU} 500 \mathrm{mg} / \mathrm{m}^{2}$ per day, both on 3 consecutive days per cycle, every 3-4 weeks was prescribed. Second as an inpatient treatment, cisplatin was prescribed as in the first schedule; however, 5-FU was prescribed at a dose of $750-1,000 \mathrm{mg} / \mathrm{m}^{2}$ as a 24-hour continuous infusion for 4 consecutive days, usually during radiotherapy. The median number of courses was 2 (range 1-10) in the chemoradiotherapy group and 3 (range 1-11) as an adjuvant to surgery in the group which underwent surgical resection. Median delay from the diagnosis to the initiation of treatment was 21 days (range 1-815). The median follow-up was 6 months (mean 11.7) and the range was 1-102 months. 366 deaths, including 51 deaths due to treatment complications (35 deaths related to surgical complications) and also 100 local recurrences, 124 distant recurrences and 6 second primary cancers were found. Median survival was 38 months (95\% CI, 26.6-49.3), 5-year overall survival rate was $42 \%$ (38.7646.16) and median event-free survival was 21 months (95\% CI, 18.2-23.8) with a 5-year event-free survival rate of $29.9 \%$ (27.07-32.67) (fig. 1, 2). In the univariate analysis, statistically significant good prognostic factors for

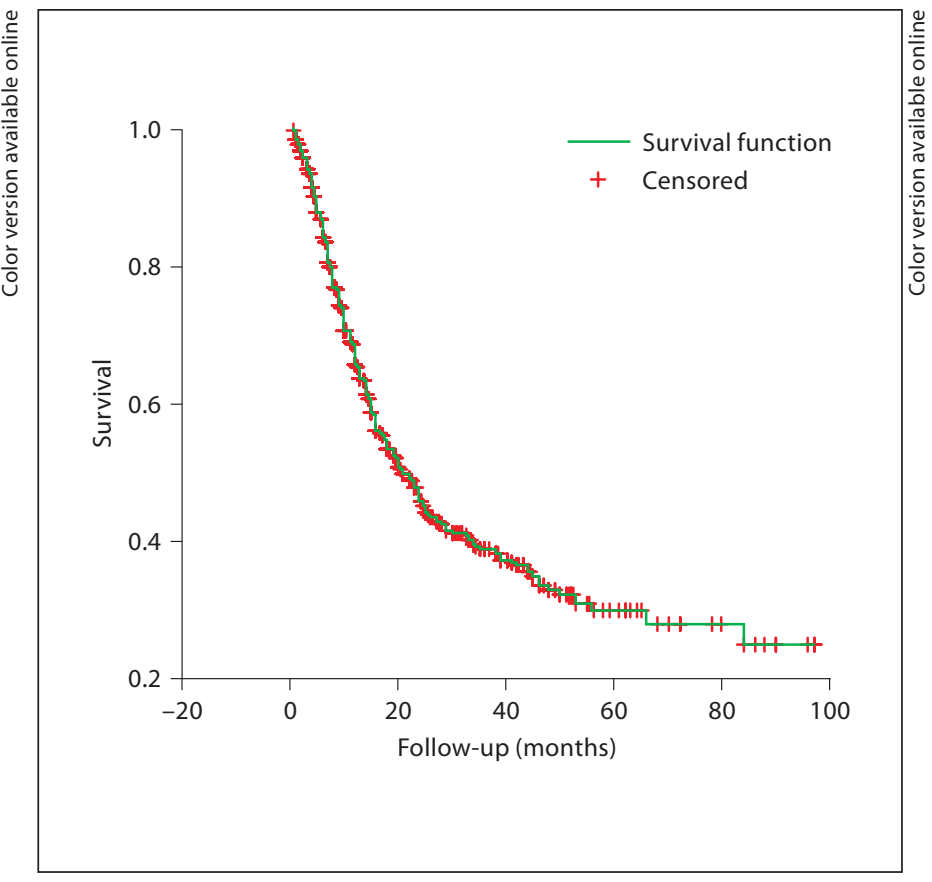

Fig. 2. Kaplan-Meier curve of event-free survival.

overall survival were patient age under 65 , female gender, epidermoid carcinoma histology, cervical or upper thoracic esophagus tumors, a body mass index above 20 and nonmetastatic stage at diagnosis. However, in the multivariate analysis, the stage at diagnosis was the only significant prognostic factor. The patients' clinical characteristics are summarized in table 2.

\section{Discussion}

Esophageal carcinoma is thought of as one of the direst neoplasms by many physicians. However, our results show that a median survival of 38 months and 5 -year survival of $42 \%$ are fairly higher than the most frequently reported figures in international publications. Although in the univariate analysis, male gender, adenocarcinoma histology, patient age over 65 , and weight loss presented as a body mass index of less than 20 exerted a significantly detrimental effect on survival, in the multivariate analysis, the stage at diagnosis was the only significant independent predictor of overall survival.

Outcomes reported in the Surveillance Epidemiologic and End Results Cancer Statistics Review (1975-1999) revealed that in the period 1992-1999, the 5-year overall survival rate for esophageal cancer (all types) was 14\%, 
Table 2. Demographic and clinical characteristics of the study population

\begin{tabular}{|c|c|c|c|}
\hline & Patients, $\mathrm{n}$ & $\begin{array}{l}\text { Median } \\
\text { survival } \\
\text { months }\end{array}$ & $\mathrm{p}$ value \\
\hline \multicolumn{4}{|l|}{ Age } \\
\hline$\leq 65$ years & $897(57 \%)$ & 45 & \\
\hline$>65$ years & $671(43 \%)$ & 28 & 0.0027 \\
\hline \multicolumn{4}{|l|}{ Gender } \\
\hline Men & $858(54.7 \%)$ & 28 & \\
\hline Women & $710(45.3 \%)$ & 48 & 0.0915 \\
\hline \multicolumn{4}{|l|}{ Histology } \\
\hline SCC & $1,456(93 \%)$ & 41 & \\
\hline Adenocarcinoma & $56(3.6 \%)$ & 14 & 0.04 \\
\hline Other & $51(3.3 \%)$ & 26 & \\
\hline \multicolumn{4}{|l|}{ Pathologic grade } \\
\hline Grade 1 & $329(21 \%)$ & 39 & \\
\hline Grade 2 & $461(29.4 \%)$ & 27 & \\
\hline Grade 3 & $174(11 \%)$ & 38 & 0.9 \\
\hline \multicolumn{4}{|l|}{ Location } \\
\hline Cervical and upper thoracic & $105(6.7 \%)$ & $>40$ & \\
\hline Middle thoracic & $480(30.6 \%)$ & 38 & \\
\hline Lower thoracic & $813(51.8 \%)$ & 29 & 0.04 \\
\hline Lower and middle thoracic & $131(8.3 \%)$ & - & \\
\hline Unspecified & $39(2.5 \%)$ & & \\
\hline \multicolumn{4}{|l|}{ Size } \\
\hline$\leq 5 \mathrm{~cm}$ & $563(36 \%)$ & 56 & \\
\hline$>5 \mathrm{~cm}$ & $389(25 \%)$ & 70 & 0.16 \\
\hline \multicolumn{4}{|l|}{ Shape } \\
\hline Circumferential & $387(25 \%)$ & 70 & \\
\hline Not circumferential & $464(29.5 \%)$ & $\approx 70$ & 0.9 \\
\hline \multicolumn{4}{|l|}{ Stage } \\
\hline Nonmetastatic (no surgery) & $738(47 \%)$ & $>28$ & \\
\hline Nonmetastatic (surgical) & $505(32 \%)$ & $>63$ & \\
\hline Metastatic (IVA and IVB) & $190(12 \%)$ & 12 & 0.0000 \\
\hline Unspecified & $135(9 \%)$ & & \\
\hline \multicolumn{4}{|l|}{ Delay to start treatment } \\
\hline$\leq 42$ days & $896(57 \%)$ & 38 & \\
\hline$>42$ days & $260(16.5 \%)$ & 34 & 0.3 \\
\hline \multicolumn{4}{|l|}{ BMI } \\
\hline$<20$ & $315(20 \%)$ & 19.5 & \\
\hline$\geq 20$ & $237(15 \%)$ & 56 & 0.01 \\
\hline Unspecified & $1,013(65 \%)$ & 44 & \\
\hline
\end{tabular}

ranging from $29.1 \%$ in patients with localized disease to $13.1 \%$ in those with regional disease and to $2.2 \%$ in those with distant disease [10]. It was reported that the median survival of esophageal cancer patients was 9 months in 1998 [11]. Survival results in different series are difficult to compare because of the mix of histologies reported and the different treatments; however, the AJCC system predicts survival differences by stage regardless of treatment (surgery plus adjuvant therapy, surgery alone or nonsurgical therapy). The 5-year overall survival rate ranges from 60 to $90 \%$ for stage I, 30 to $60 \%$ for stage II, 5 to $30 \%$ for stage III and 0 to $20 \%$ for stage IV [10]. A recent population-based survey by Eurocare shows that the mean 5 -year relative survival is about $12 \%$ for European esophageal patients diagnosed between 1995 and 1999 [12].

In Japan, some authors reported 5-year survival rates at around $40 \%$, claiming that treatment results are somewhat better in Japan than in other countries [13-15]. Aside from Japan, no other notable publications relating esophageal carcinoma to any suggestion indicative of survival superiority based on country or ethnicity could be found in English language publication resources. Of course there has been emphasis on different survival rates among countries based on wealth and health system [12]. In addition, although this is not related to ethnicity, the outcome of esophageal cancer treatment in blacks is poorer than in whites, according to some reports published in western countries $[5,11]$.

These findings could be considered reliable in relation to similar higher treatment outcome and survival of patients in the local northeast region of Iran, which is representative of all Iran. In judging this, we must consider all the potential strengths and limits of the study:

(1) Northeast Iran is considered one of the areas most ravaged by of esophageal carcinoma in Iran. This is part of the Caspian littoral which, based on international statistics, is known as one of the endemic areas of esophageal carcinoma in the world [3-5].

(2) This study is the first and the largest of its kind. No other studies from nonwestern countries have reported such a large number of cases.

(3) This is a single-institutional hospital-based registry study and so it is not as powerful as a populationbased study or at least a multicenter cancer survival analysis. However, the hospitals engaged in the treatment of esophagus cancer are the most accessible centers in the area and do not benefit from any referral preferences policies. Therefore, these data could be deemed representative of the entire population with esophagus cancer in the area. In spite of this, based on some local (cancer registry reports of the Khorasan province, Iran) and national statistics, this collection might include no more than $60 \%$ of all diagnosed esophagus cancer patients during this period [16].

(4) To lower the level of any selection bias, this study attempted to include all consecutively referred patients who had been diagnosed with esophageal carcinoma. In contrast to clinical trials, there were no important exclusion criteria that decreased the eligibility of patients based on this study's framework. 
(5) The median follow-up of 6 months may be considered as a major weakness of this study. A great number of patients were lost to follow-up, although some surviving patients were followed up for more than 8 years.

In this study, some possibly valid determinants and explanations indicating a better outcome are as follows:

(1) Most researchers believe that the prognosis for women is brighter $[5,11]$. In contrast to international reports, the number of female patients in northeast Iran is almost equal to that of male patients.

(2) Age has been recognized as a significant prognostic factor by most researchers in that the outcome of patients older than 65 has been reportedly worse [11]. While cancer of the esophagus rarely occurs before the age of 65 in western communities, in our study population, the median age of 61.5 is significantly lower.

(3) Access to treatment facilities is a known important factor affecting cancer survival. As seen in table 1 and described earlier in the text, this is not a major contributing factor in this study's higher survival rate since treatment methods and modalities in Iran are not very different from treatment recommendations typically offered, for example, in the USA [5, 17].

(4) Studies suggest that most of the differences in survival among cancer populations are attributable to differences in disease stages at diagnosis [12]. In this study, the stage of the disease was the most important predictor of outcome, as is generally reported by most researchers. Although, in our patients, staging procedures were not as thorough or as up to date as in most recent trials, at least $12 \%$ of these patients had metastatic disease at diagnosis. We think that there were certainly some other understaged metastatic cases that would have been shifted to stage IV if more sophisticated staging methods had been adopted. In addition, a significant number (41\%) of those patients whose staging was performed surgically, were in stage III as many benefited from neoadjuvant treatments.
(5) The variation in the distribution of cancer histotype could be another reason for the geographic variation in cancer survival [12]. Although the majority of cases in this study had SCC, no significant survival differences have been noted between adenocarcinoma and similarly staged SCC patients [5].

(6) Squamous cell carcinoma shows striking variations in geographic distribution, reflecting exposure to specific poorly defined environmental factors. While the main contributing risk factors in western countries are alcohol and smoking, in some other endemic areas the risk factors may be different. Especially in Iran, patients have a negligible history of alcohol consumption and use of cigarettes or chewing tobacco, but they may be exposed to other carcinogens and nutritional deficiencies [1820].

One of the suggested culprits in the pathogenesis of esophagus SCC in high-incidence areas in Asia and South Africa is human papillomavirus (HPV) infection [21]. While this oncogen has been reported to be involved in $70 \%$ of the cases in some high-incidence areas, it contributes least in low-incidence areas. In Iran, researchers have detected viral serotypes in $36.6-52 \%$ of esophagus SCC samples [22, 23]. It has to be determined if this virus has any relation to a better outcome of esophageal cancer.

In conclusion, the survival rate difference and better outcome of esophageal cancer patients in northeast Iran must be considered seriously as this is known to be an endemic area of esophageal cancer in the world. Future investigations of whether etiologic factors or ethnicity have any contributing effect are worthwhile.

\section{Acknowledgment}

This study was supported by a grant from the Vice Chancellor for Research of Mashhad University of Medical Sciences (grant number 84083).

\section{References}

1 Crew KC, Neugut AI: Epidemiology of upper gastrointestinal malignancies. Semin Oncol 2004;31:450-464.

2 Shah MA, Schwarts GK: Treatment of metastatic esophagus and gastric carcinoma. Semin Oncol 2004;31:574-587.

3 Parkin D, Muir C, Whelan S, et al: Cancer incidence in five continents. Lyon, France, IARC Scientific Publications, 1992.
4 Munos N, Day NE: Esophageal cancer; in Cancer Epidemiology and Prevention, ed 2. New York, Oxford University Press, 1996, pp 681-706.

5 Posner MC, Forastiere AA, Minsky BD: Cancers of the gastrointestinal tract; in Cancer Principles and Practice of Oncology, ed 7. Philadelphia, Lippincott Williams \& Wilkins, 2005, pp 861-909.
6 Ries I, Kosary CL, Hankey, et al: Cancer Statistics Review 1973-1994, NIH Publications No 97-2789. Bethesda, Department of Health and Human Services, 1997.

7 American Joint Committee on cancer: Manual for Staging of Cancer, ed 6. New York, Springer, 2002.

-8 Kaplan E, Meier D: Nonparametric estimation from incomplete observations. J Am Stat Assoc 1958;53:457-481. 
9 Cox DR: Regression models and life tables. J R Stat Soc 1972;B34:187-220.

10 Abdalla K, Pisters PWT: Staging and preoperative evaluation of upper gastrointestinal malignancies. Semin Oncol 2004;31:513529.

11 Denittis AS: Esophagus; in Principles and Practice of Radiation Oncology, ed 4. Philadelphia, Lippincott Williams \& Wilkins, 2004, pp 1282-1304.

12 Berrino F, De Angelis R, Sant M, et al: Survival for eight major cancers and all cancers combined for European adults diagnosed in 1995-99: results of the EUROCARE-4 study. Lancet Oncol 2007;8:773-783.

13 Kodaira T, Fuwa N, Itoh Y, et al: Multivariate analysis of treatment outcomes in patients with esophageal carcinoma treated with definitive radiotherapy. Am J Clin Oncol 2003; 26:392-397.
4 Akiyama $\mathrm{H}$, Tsurumaru M, Udagawa $\mathrm{H}$, et al: Radical lymph node dissection for cancer of thoracic esophagus. Ann Surg 1994;220: 364-372.

15 Aba M, Aikou T, Yoshinaka H, et al: Longterm results of subtotal esophagectomy with three-field lymphadenectomy for carcinoma of the thoracic esophagus. Ann Surg 1994; 219:310-316.

16 Islamic Republic of Iran, Ministry of Health and Medical Education: Iranian Annual of National Cancer Registration Report, 2004.

17 Daly JM, Karnell LH, Menck HR: National cancer database report on esophageal carcinoma. Cancer 1996;78:1820-1828.

18 Van Rensburg SJ: Epidemiology and dietary evidence for a specific nutritional predisposition to esophageal cancer. J Natl Cancer Inst 1981;67:243-251.
19 Castellsague X, Munoz N, De Estefani E, et al: Independent and joint effects of tobacco smoking and alcohol drinking on the risk of esophageal cancer in men and women. Int J Cancer 1999;82:654-657.

20 Ajani JA: Preoperative therapy for patients with respectable squamous cell carcinoma of the esophagus. Ann Surg Oncol 2002;9:605606.

21 Sur M, Cooper K: The role of human papilloma virus in esophageal cancer. Pathology 1998;30:348-354.

-22 Moradi A, Michel De Viliers E, Mokhtari Azad T, et al: Detection of human papilloma virus DNA by PCR in esophageal SCC from Torkman Sahra, Northeast of Iran. Iran Biomed J 2002;6:19-23.

23 Farhadi M, Tahmasb Z, Merat S, et al: Human papilloma virus in SCC of esophagus in a high-risk population. World J Gastroenterol 2005;11:1200-1203. 